\title{
17 Learning to talk about motion UP and DOWN in Tzeltal: is there a language-specific bias for verb learning?
}

\author{
Penelope Brown \\ Max Planck Institute for Psycholinguistics, Nijmegen, The Netherlands
}

\section{$1 \quad$ Introduction}

This chapter discusses a case of language-specific semantics, and proposes a language-specific learning process to account for how children acquire the relevant expressions. The language-specific semantics is that of the vocabulary involved in the "uphill/downhill" system of spatial description in the Mayan language Tzeltal. Tenejapan speakers of Tzeltal ${ }^{1}$ speak as if the whole world tilted down northwards; thus one can speak of the "uphill" end of a table, for example, using the general South/North slope of the land as a frame of reference for describing spatial relations on the horizontal. I will focus on that subpart of the system which has an element of verticality: the verbs, directional adverbs, and nouns of this system, which are used both for spatial relations arrayed along a vertical axis and for those arrayed along a horizontal axis derived from the overall slope of the land. The vocabulary at issue is set out in table 17.1; for convenience I will refer to this as the UP/DOWN vocabulary of Tzeltal, but it must be borne in mind that the role of the vertical axis is precisely what is being treated as problematic in this discussion. I will relate the acquisition of this system to currently controversial issues in the language acquisition literature: the strategies children adopt for learning words, the possible biases they begin the task with, and the role of universal semantic features like "vertical" in this process.

Spatial language and cognition have provided a key focus for theories of word learning in recent years. Work in linguistic theory (Talmy 1985), in language acquisition (Slobin 1985), and in developmental psychology (Piaget \& Inhelder 1967) has converged on the position that there is a universal set of basic spatial concepts, and that in the spatial domain cognitive development precedes, and provides the basis for, language development. However, the accumulation of crosslinguistic evidence by Bowerman, Choi, de León, and others ${ }^{2}$ of children's very early language-specific spatial meanings has made a convincing case for the necessity to rethink our theories of how chil- 
dren approach the word learning task. In particular, it casts doubt on two major lines of theorizing about how children learn spatial word meanings. The first is that children's early hypotheses are guided by a universally given set of precomposed, "natural" prelinguistic concepts (H. H. Clark 1973, Slobin 1985). Until recently there was a consensus that such prelinguistic concepts provide ready-made semantic units, at least in the domain of spatial language. ${ }^{3}$ Many theorists have been unable to see how children can learn word meanings without substantial preconceptions about the semantic content. There is still much disagreement about the degree to which children need a privileged set of universal notions to start them off on the language-learning task, vs. the extent to which (and indeed, how) the process of learning the words of a language and their appropriate contexts of use can actually help children build the concepts they encode. (See Levinson, ch. 19 of this volume, for a discussion of the levels of difficulty imposed by such a task.)

A second, related, theoretical debate concerns the nature of children's initial hypotheses about the meaning of a new word: what sorts of biases do learners bring to the task? As a solution to Quine's problem of the indeterminacy of reference, ${ }^{4}$ many biases - presumptions about meaning - have been attributed to the language-learning child for the learning of concrete nouns. ${ }^{5}$ Some theorists have tried to extend this approach to verb learning. One such suggestion has been that children in general have a strategy of starting with simpler (more general, "light") verb meanings, going on to learn more complex (specific) meanings by adding restricting features (E. V. Clark 1973, 1993). ${ }^{6}$ Others have extended the idea of pregiven biases for noun learning to postulate that children may have predispositions that they apply specifically to the task of verb learning (e.g. Golinkoff, Hirsh-Pasek, Mervis, Frawley, \& Parillo 1995). Difficulties with these hypotheses have prompted other theorists to reject the idea of word learning biases altogether, and to emphasize the crucial role of context, interaction, and the ascription of communicative intent in how children learn word meanings (Tomasello 1992, ch. 5 of this volume; Tomasello \& Merriman 1995).

In this chapter I bring data from another language to bear on these questions. I will discuss how children learn the Tzeltal spatial vocabulary for UP/DOWN relations. I argue that:

1. Tzeltal children do not necessarily start with a putatively universal, perceptually based vertical meaning for these nouns and verbs. From their earliest uses of the UP/DOWN vocabulary, children use the words with language-specific landslope meanings as well as with vertical meanings. Rather than verticality, a sense of "place" is the semantic core to the meanings children attribute to these words.

2. The word learning biases proposed in the literature are not applicable to 
Tzeltal children's learning of this vocabulary. Those proposed for nouns would not help with Tzeltal UP/DOWN nouns (which denote relations, not concrete objects), while those for verbs (e.g. light verbs in children's one- and two-word stages) would wrongly predict which verbs children learn first in this language. Tzeltal children generally learn semantically specific verbs first, and initially stick to very specific meanings for the UP/DOWN verbs they learn.

The proposal put forward here is that the highly specific nature of Tzeltal verbs influences the children's hypotheses about what kinds of meanings verbs can have. This suggests that a different kind of bias from those discussed above may be adopted by the children: a language-specific bias towards verb specificity, induced on the basis of verbs they have already learned. Two seemingly contradictory observations about children's early meanings for the spatial verbs of Tzeltal motivate this proposal. On the one hand, Tzeltal children's UP/DOWN vocabulary shows early sensitivity to the semantic structure of the language they are learning: the meanings they associate with these verbs and relational nouns are from the first attached to the slope of the land, and to particular places; there is no evidence of an initial preference for the vertical meaning. On the other hand, children's meanings for the verbs remain for a long time too specific, and errors of interpretation/production (using and understanding the verbs to mean 'ascend/descend' with respect to the local slope of land rather than the overall (South/North) slope of land direction) are evident in some children as late as age 7 or 8 .

The Tzeltal data presented here complement those of de León (ch. 18 of this volume) for the closely related language Tzotzil. De León focuses on the language-specific nature of Tzotzil children's first descriptions of events involving vertical paths, and the relatively late emergence of intransitive motion verbs and directionals encoding UP/DOWN paths. My examination of Tzeltal starts from the beginning of children's acquisition of intransitive motion verbs around the age of 2 , and summarizes the language-specific nature of their acquisition of the UP/DowN system in general. I then draw on these findings, as well as those of de León (1994) for the Tzotzil Absolute system, to speculate about the consequences of the semantic structure of languages of this Mayan type for children's initial relational word learning hypotheses.

The spatial vocabulary of Tzeltal is dominated by an Absolute system of spatial reckoning, that is, a system whose coordinates are extrinsic to the 
Table 17.1. Vertical location and UP/DOWN motion in Tzeltal

\begin{tabular}{|c|c|c|c|c|c|}
\hline & \multicolumn{2}{|c|}{ MOTION } & \multicolumn{2}{|c|}{ STASIS } & \multirow{2}{*}{$\begin{array}{l}\text { POSITION } \\
\text { verb root }\end{array}$} \\
\hline & verb & directional & $\begin{array}{l}\text { relational noun: } \\
\text { unpossessed }\end{array}$ & $\begin{array}{l}\text { relational noun: } \\
\text { possessed }\end{array}$ & \\
\hline UP & $\begin{array}{l}\text { mo } \\
\text { 'ascend' }\end{array}$ & $\begin{array}{l}\text { moel } \\
\text { 'ascending' }\end{array}$ & $\begin{array}{l}\text { ajk'ol, or kajal } \\
\text { 'uphill' }\end{array}$ & $\begin{array}{l}y \text {-ajk'ol } \\
\text { 'its-above-side' } \\
s \text {-ba 'its top or } \\
\text { uphill side' }\end{array}$ & $\begin{array}{l}\text { kaj 'be above' } \\
\text { toy* 'be high up' } \\
\text { etc. }\end{array}$ \\
\hline DOWN & $\begin{array}{l}\text { ko } \\
\text { 'descend' }\end{array}$ & $\begin{array}{l}\text { koel } \\
\text { 'descending' }\end{array}$ & $\begin{array}{l}\text { alan } \\
\text { 'downhill' }\end{array}$ & $\begin{array}{l}y \text {-anil } \\
\text { 'its underneath or } \\
\text { downhill side' } \\
y \text {-e'tal 'its downhill } \\
\text { side' }\end{array}$ & $\begin{array}{l}\text { pek' 'be low } \\
\text { down' } \\
\text { toy* 'be deep } \\
\text { down,' } \\
\text { etc. }\end{array}$ \\
\hline
\end{tabular}

Note: *toy means either 'high up' or 'deep down,' i.e. far from some reference level (usually ground level).

spatial scene, as in the familiar cardinal (North/South/East/West) systems (see Levinson, ch. 19 of this volume). In the Tzeltal system, an "uphill/downhill" coordinate abstracted from the lay of the land is used to reckon spatial relationships on the horizontal in both small-scale and long-distance space (Brown \& Levinson 1993a; Levinson, ch. 19 of this volume). In some respects the system is a bit like a cardinal direction system, with UP equated roughly with South, DOWN with North. ${ }^{7}$ This system is used in lieu of a projective Front/Back/Left/Right system, which does not exist in this language. ${ }^{8}$ The spatial vocabulary dedicated to this Absolute system (which is what I am referring to as the UP/DOWN vocabulary) is encoded in noun and verb roots, and is given in table 17.1. It includes the Motion + Path conflating intransitive verb roots ${ }^{9} \mathrm{mo} / k o$ (roughly translatable as 'ascend/descend,' i.e. 'move in a South/North direction'), their transitivized counterparts (mo-tes/ko-tes 'make ascend/descend'), and directional adverbials transparently derived from them (moellkoel 'up(hill)wards/down(hill)wards'). It also includes relational nouns denoting 'uphill/downhill' regions, which may be either unpossessed (and hence only implicitly relational) or possessed and hence explicitly relational ('uphill/downhill in relation to $X$ '). This same vocabulary applies to spatial relations on the vertical axis. The system also has an axis transverse to the South/North UP/DOWN one, undifferentiated at the two ends; both directions along this axis are labelled jelawel 'acrossways' and motion along it jelaw 'going across.' 10 Using this system, one speaks of a Figure (the object being located) as being 'uphill/downhill/across' in relation to a Ground (the reference point). (See figure 17.1.) 


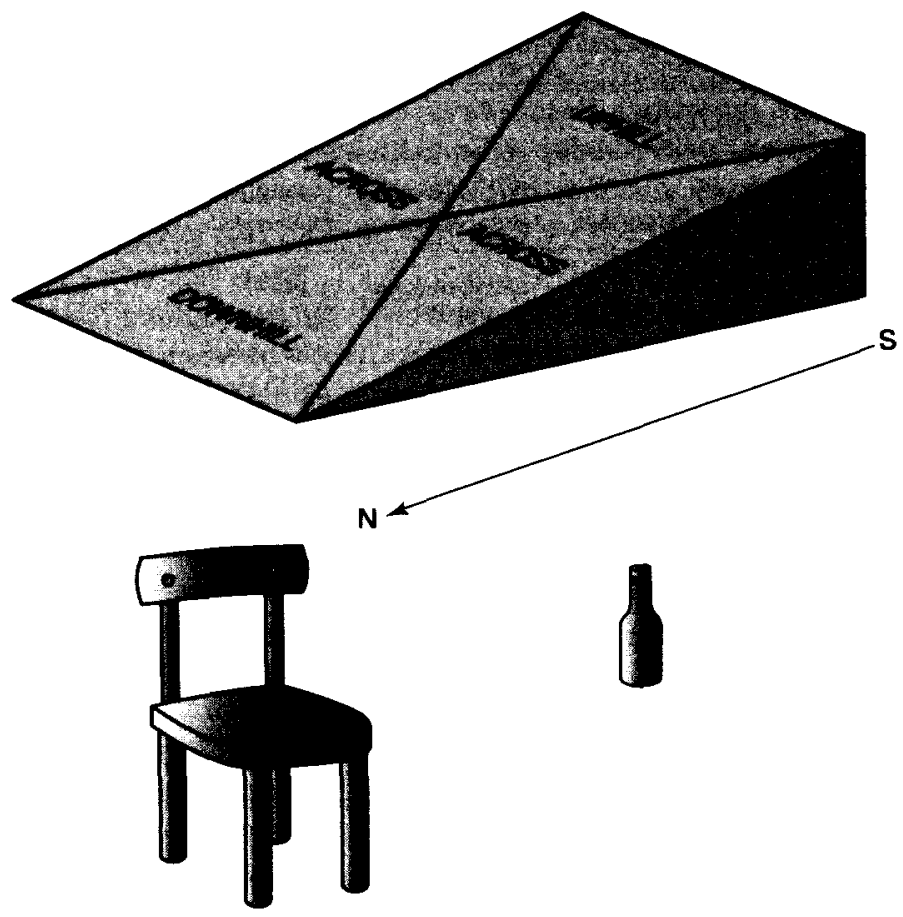

"The bottle is uphill of the chair"

Fig. 17.1 Tzeltal uphill/downhill system.

Such a system poses interesting problems to the learner. To use an Absolute system in an adult-like way requires some fairly complex cognitive abilities: in Piagetian terms the system is Euclidean, utilizing precise fixed angles and precise geometric constructions like "a specific angle around a fixed direction." Since horizontal spatial relations beyond those of immediate proximity are routinely encoded using this system, it requires speakers to maintain absolute orientation at all times, so that they always know where "uphill" and "downhill" are, even at night and in unfamiliar places (Brown \& Levinson 1993a; Levinson 1996).

To this cognitive complexity we must add the semantic complexity of the UP/DOWN vocabulary of Tzeltal, which resides in the variety of meanings it can have in context. Since the vertical axis in Tzeltal semantics is confounded with the Absolute system of spatial reference, when people say the Tzeltal equivalent of "Go up" or "It's descending" or " $X$ is uphillwards of $Y$ " they can mean either vertically or horizontally along a coordinate 
abstracted from the lay of the land, roughly South/North. ${ }^{11}$ To make things even more difficult, there is a third source of ambiguity: the UP/DOwN axis may also be abstracted from the local slope of land even when it deviates from a South/North direction. In both the Absolute and the local uses, the spatial relations referred to may actually be on the horizontal, with Figure and Ground on the same level, even though they are based conceptually on the slope of the land. There is thus a three-way ambiguity in the frame of reference underlying use of these spatial terms: UP/DowN with respect to (1) the vertical, (2) the conceptually abstract overall downhill slope of land from South to North, and (3) the local slope of land (which may deviate from the overall South/North slope).

Learning spatial language involves two distinct tasks: learning the relational categories and the language's labels for them, and learning the frames of reference for calculating spatial relations employed in the language community (Levinson 1996). But the Tzeltal child is simply presented with language in use: she hears motion verbs used in contexts like 'Descend!' (from a tree, a bed, the uphillwards [i.e. southwards] house, etc.), 'He ascended' (into the bus, to the uphillwards (southern) fields, etc.), 'She descended from San Cristobal,' 'The rain is descending' [i.e. coming from the south], 'Bring me the machete standing uphillwards [south] of the door,' 'It [a puzzle piece] goes in downhillwards, in the downhillwards (i.e. northwards) hole.' From utterances like these, paired with their contexts, the child must abstract a sense of "up/down" which can apply equally to spatial relations which are vertical or which are arrayed along the axis corresponding to the slope of the land, whether or not the objects being talked about are on a slope or on the horizontal. ${ }^{12}$

The Tzeltal child also has to learn to differentiate these overlapping distinctions from the meanings of other intransitive Motion+Path verbs, in particular to distinguish path types on the horizontal which differ only in their anchoring frame of reference: path towards/away from the speaker ("come/go"), as opposed to path oriented along the "uphill/downhill" axis ("ascend/descend") or at right angles to it ("go across"). As these distinctions go well beyond the sorts of meanings predicted for basic motion verbs crosslinguistically (Talmy 1985), this is another potential source of difficulty for these verbs.

This raises interesting questions for language acquisition. Which of the uses of UP/DOWN do Tzeltal children acquire first? Do they go for verticality or for lay-of-the-land, and, if lay-of-the-land, is it local or long-distance? Is there any evidence of pressure on their early word-meanings from a universal prelinguistic concept of verticality? If there is in fact a salient prelinguistic concept of "upness" (Bloom 1973) or Vertical Motion (Nelson 1974), Tzeltal requires children to extend it to the lay of the land and to the horizontal. 
How is this ambiguity handled, and, in particular, how does the Absolute system develop for use on the horizontal, in relation to meanings clearly involving verticality? How long does it take children to develop the full adultlike Absolute system?

In this chapter I begin to try to answer these questions, and to account for children's early meanings for the Tzeltal intransitive path verbs and relational nouns whose core semantics includes reference to a vertical axis. The data are drawn from a longitudinal corpus of natural language production from children aged 1;6 to 4;6 in five Tzeltal families, as well as from elicited production and comprehension tasks performed by these and other children between the ages of $4 ; 0$ and $12 ; 0 .^{13}$

Children's learning of the UP/DOWN vocabulary

\subsection{Natural production data}

The vocabulary with which the Absolute system is constructed (given in table 17.1) begins to appear in children's speech at around the age of $2 ; 0$ (two years, zero months), in some cases when the child is still in the one- or two-word stage. ${ }^{14}$ This vocabulary is not very frequent in children's speech (nor indeed is it frequent in adult input to children), ${ }^{15}$ and it remains restricted to specific local contexts at first - 'ascend/descend' to a set of particular places - as the examples in table 17.2 illustrate. From the start these places are spatially related to their reference points either vertically (the terms being used in collocation with verbs of falling, or in contexts of climbing into trees, up onto furniture, etc., as shown in table 17.3) or horizontally (landslope; e.g. used for movement between houses, movement of toy cars on the flat patio, movement in relation to the household layout, as in table 17.2). The children are thus apparently willing to postulate language-specific meanings for verbs from the beginning: in this case, meanings for Motion+Path verbs distinguishing four "kinds of motion" along the ground on the basis of directionality, with motion towards/away from speaker ("come/go") distinguished from motion in relation to certain ("uphill/downhill") places. This supports the conclusion of Choi \& Bowerman (1991) that there is no shared starting point for children's meanings of such path-conflating verbs across languages.

The relational nouns ajk'ollalan 'up(hill)/down(hill)' also appear in Tzeltal children's speech at around age 2;0, and are used at first to label places (e.g. 'downhill' = where the family cornfields are) and to identify persons as associated with specific "uphill/downhill" places ('granny downhill').

Between the ages of 2 and 3 children's usage of these UP/DOWN terms 
Table 17.2. Examples of "ascend/descend" verbs and directionals in their landslope senses (pooled data from six children) Criteria: clear meaning in context; not a repeat of prior utterance. Verb stems and directionals are shown in italics.

\begin{tabular}{|c|c|c|}
\hline $\begin{array}{l}\text { Name } \\
\& \text { age }\end{array}$ & Example & Context \\
\hline Lus 2;0 & $\begin{array}{l}\text { moem bel. } \\
\text { 'It has ascended away.' }\end{array}$ & $\begin{array}{l}\text { re a toy car just mentioned as "going to } \\
\text { San Cristobal" (she is playing with } \\
\text { another child with toy cars on the flat } \\
\text { patio) }\end{array}$ \\
\hline Xaw 2;3 & $\begin{array}{l}\text { ko ko xi ini. 'Descend, descend it says } \\
\text { here.' }\end{array}$ & as she wheels toy along floor \\
\hline Xan 2;4 & ya koon. 'I'm descending.' & $\begin{array}{l}\text { announcing intention to go to downhill } \\
\text { house }\end{array}$ \\
\hline Xan 2;4 & $\begin{array}{l}\text { kuchoj bel i alali ya mo bel. 'The doll } \\
\text { was carried away, (she) ascends away.' }\end{array}$ & up slope towards other house \\
\hline Pet $2 ; 4$ & $\begin{array}{l}\text { kinam a mo bel. } \\
\text { 'My wife ascend(ed) away.' }\end{array}$ & $\begin{array}{l}\text { claiming that his imaginary wife has } \\
\text { gone "uphillwards" }\end{array}$ \\
\hline Pet 2;5 & $\begin{array}{l}\text { ko tal, ilaik, } k o \text { la 'wil li'i. } \\
\text { 'It came down, look, it came down } \\
\text { here.' }\end{array}$ & re a toy down the hillside \\
\hline Pet $2 ; 5$ & koan bel. 'Descend away.' & to house below \\
\hline Xan 2;5 & $\begin{array}{l}\text { ya xmoon ek . . koixix tal. } \\
\text { 'I'll go up too. . . . They have come } \\
\text { down.' }\end{array}$ & $\begin{array}{l}\text { between lower (North) and upper } \\
\text { (South) house }\end{array}$ \\
\hline Nik 2;6 & mo tal ja' ini. 'This has ascended here.' & a toy car \\
\hline Pet 2;6 & koon ta alan. 'I descend to downhill.' & i.e. to the downhill house \\
\hline Xaw 2;8 & e koon. je mo. 'I descend. (I) ascend.' & between houses \\
\hline Mal 2;8 & $\begin{array}{l}\text { ya } x \text { moonix bel jo'tik a. 'We are } \\
\text { ascending away now.' }\end{array}$ & to other house \\
\hline Xaw 2;9 & $\begin{array}{l}\text { ya xmoonix bel a. } \\
\text { 'I'm now ascending away there.' }\end{array}$ & to other house \\
\hline Xan 2;9 & $\begin{array}{l}\text { ya xkoonix bel a ... jo, banti moon tal. } \\
\text { 'I'm going up away. } \mathrm{Hm} \text {, where do I } \\
\text { ascend coming.' }\end{array}$ & up/down local slope \\
\hline Mal 2;9 & $\begin{array}{l}\text { jich koonix tukeli. } \\
\text { 'Thus l've descended by myself.' }\end{array}$ & to other house \\
\hline Xaw 2;11 & ya jko bel. 'I descend awayward.' & to other house \\
\hline Nik 2;11 & $\begin{array}{l}\text { ma k'an koix tal. } \\
\text { '(He) doesn't want to come down.' }\end{array}$ & from other house \\
\hline
\end{tabular}


Table 17.2 (cont.)

Name

$\&$ age

Example

Context

Lus 3;0 ya xmoix bel te Nikoe. 'Nik is going up away [to his house].'

Nik's house is uphillwards (South) from where she is.

Lus 3;1 ya laj mo bel ta karo ek i. 'He's ascending away in the car.'

Nik 3;1 xko yuch', ... moix bel. 'He came down to drink, . . . he has gone up.'

re her cousin in toy car

between houses (kitchen downhill from sleeping house)

Lus 3;2 ja' i li' xtal koel ta karetera. 'It's that it's car on road coming downhill here on the road.'

Xaw 3;2 ko xan tale. '(She) descended again.'

from upper house to lower

Xan 3;4 ya sujt koel stukel. 'He's going back

to other house down alone.'

Lus 3;6 ya to mo xan bel. 'I'm going up away again.'

Lus 3;6 ya xmo bel ta k'altik ya'tik. 'She's ascending away to the fields now.'

Lus 3;6 ma me xtalat, sujtan me te koel ine. 'Don't come (here), return to down there.'

to other house

re mother going up to cornfields

telling her playmate to go to a place downhillwards from where they are

Lus 3;8 ay la yich'bet moel ye i a'karo. 'He took your car up.'

her cousin took toy car uphill to his house

Lus 3;8 moan bel te' a ini ... moan bel Nik. 'Go on up there ... go on up, Nik.'

Nik 3;9 ma me tal koel ya'tik, mo bel ta jnatik ya'tik ch'in Antun i . . 'He (Antun) towards his other house didn't come down now, he ascended contrasting the respective locations of two houses away to our house.'

Nik 4;2 ya kich' moel ta jmel. 'I'll take it upwards, for good.'

claiming a toy he wants to take home to house

very closely matches that in the input they hear; I have found no examples in this period of clearly novel usage, nor of errors. This is in contrast to the children's first verbs at the one-word stage, which are occasionally overgeneralized. ${ }^{16}$ The relative infrequency in the children's speech of 'ascend/descend,' especially in its landslope sense, means that we cannot be certain from this early production data how flexibly children use them whether, for example, they have simply memorized a list of contexts or placename collocations for which molko are used to describe motion, or have really generalized to an axis based on the land slope. 
Table 17.3. Examples of "ascendldescend" verbs and directionals in their vertical senses (pooled data from five children). Criteria: clear meaning in context; not a repeat of prior utterance. Verb stems and directionals are shown in italics

Name

\& age

Example

Context

Xan 2;0 ch'ay koel, ma 'tam. 'It fell down, don't pick it up (ball).'

from $2 ; 0$ to $2 ; 5$ she always uses koel with falling verbs and with nothing else at this stage; no contrast with moel

Xan 2;3 moon. 'I ascend.'

Lus 2;6 kojtes yakan i. 'Lower its foot' [lit. up onto chair 'make it descend'].

Lus 2;7 moix tal. '(They) have ascended coming.'

re camera tripod, the legs of which "ascend" and "descend"

toy animals up onto table into toy corral

Pet 2;7 moik laj ta te', . . moon ta te', koon tal. up/down into trees

'They ascended the tree,... I climb the tree, I descend.'

Pet 2;7 mootik ta karo, xi.

'We ascend (in)to the car, he said.'

Xan 2;8 ya to kojtes alali. 'I'll lower my doll.' i.e. I'll untie it and let it down off my kojtesben tal. 'Lower it (doll off back) for me.'

Mal 2;9 ay binti mo bel ta 'ni'. 'There's something (that) ascended away (in)to your nose.'

Nik 2;11 ile' koix tal. ma jk'an koix tal. 'Look (she) descended. I don't want to descend.'

Lus 3;2 moix muti. 'The chicken ascended.' into tree

Lus 3;3 mo laj tal ta te' eki, ... ban tzaka koel. chicken, up/down into trees 'It ascended (in)to the tree ... go grab it down.'

Xan 3;3 li' mo xan tal, koel xan ma xko. 'Here it toy car up/down hill of sand ascended coming, down again it doesn't descend.'

Xan 3;3 moemon ta regla jo'tik. 'We have ascended (on)to the boards.'

Xan 3;3 ay skoral ek, la xluch koel ye ini yala xulub. 'He has a corral too, he has lowered his little horns [as if to fight with them].'

Lus 3;6 moan tal $i$ anton, ya jkuchat bel. 'Come ascend X'an, I'll carry you away.'

she and her playmate having climbed onto pile of stacked boards toy cow she has put into a toy corral

up into large toy wooden car they can climb into 
Table 17.3 (cont.)

Name

\& age Example Context

Lus 3;6 ja' yala ch'ujt li' ni, tzisbil koel li' ini. 'It's its little stomach here, sewn

re sewing on her doll's skirt, which goes downwards here.'

Lus 3;8 mo ta jtzek, tal mook ta jtzek. 'It downwards across the stomach.

a bug climbing upwards on her skirt ascended my skirt, it came to ascend my skirt.'

Lus 3;10 ya moon ta yutil k'an moon ta yut ek. toy car they can climb into 'I ascend into (the toy car), he wants to ascend in(to it) too.'

Lus 3;11 ya jpet tal koel me'tik; maili i. 'I'll carry telling researcher she'll carry her cousin (her) down, Mrs.; wait.' from her bed to researcher

Table 17.4. Summary of production, ages 2-4, for Absolute vocabulary

First appearance of terms: $\mathbf{x}$

Productive use, in contrast sets, with no "errors": yy

$\mathrm{n}=3$

\begin{tabular}{lllll}
\hline & & & & directionals \\
('ascending/ & unpossessed \\
('ascend/descend') & descending') & $\begin{array}{l}\text { possessed nouns } \\
\text { ('its-uphill,' 'its- } \\
\text { ('uphill/downhill') }\end{array}$ & $\begin{array}{l}\text { downhill,' 'above } \\
\text { it,' 'below it' [ABS] }\end{array}$ \\
\hline $2 ; 0-2 ; 5$ & x & x & x & \\
$2 ; 6-3 ; 0$ & yy & yy & yy & x \\
$3 ; 1-3 ; 6$ & & & yy \\
$3 ; 7-4 ; 0$ & & & & \\
\hline \hline
\end{tabular}

Table 17.4 summarizes the natural production data from three of the children for UP/DOWN verbs and nouns. The children appear to have mastered the semantic contrasts of the terms in the Absolute system by age 3, by which time there is evidence that they are not just imitating the input, but are using the terms for novel situations. They have acquired the syntax of possessed nouns by at least 3;6, and are using the vocabulary explicitly relationally by this time, in at least some contexts (saying things like " $F$ [a Figure object] is uphillwards of $\mathrm{G}$ [a Ground object or reference point]" or " $F$ is moving uphillwards in relation to G"). By age 3;6 to 4;0, all three children produce the requisite vocabulary in contrast sets, in different contexts, 
in different grammatical constructions (using it with different aspectual, causative, or subjunctive affixes), in both possessed and unpossessed forms, and in some novel (not modelled by an adult) contexts (see tables 17.2 and 17.3 for examples).

In order to produce such novel utterances the children must have the rudiments of an Absolute system of spatial reference: they must be able to use the lay of the land to establish a vector in a fixed direction with differentiated "up" and "down" ends as the basis for deciding where an object is in relation to the Ground object. The children's production data analyzed so far is compatible with use of the local slope of land to establish the Absolute axis; I don't yet have clear evidence from children's natural production that they have abstracted an overall (South to North) slope of land axis for the system. They can, however, by at least age 4;0, accurately point to ajk'ol 'uphill' and alan 'downhill' across considerable distances and not necessarily coinciding with the local slope, showing that their geographical knowledge already provides the basis for an abstract geographical Absolute system, at least from their home base. Their use of the system is thus to a limited extent "productive": by about 3;6 children can use this system to relate objects and events spatially to places and people familiar to them, amounting (as an approximation) to some twenty or thirty fixed places (their own households and those of their relations, the fields of their family and those of other families who work with their family, the school, medical clinic, shop, etc.). Just when this extends to any place is still unclear; children undoubtedly differ in this respect.

The data show that Tzeltal children do not make semantic overgeneralizations on the basis of putatively universal spatial notions like vertical UP/DOWN. They do not generalize the UP/DOWN path vocabulary to events where vertical motion is involved in the event but is not overtly lexicalized in the adult language (e.g. to the contexts of posture changes, lifting, and carrying, as is also demonstrated by de León for Tzotzil; 1994, ch. 18 of this volume). The child's first meanings for the UP/DOWN path vocabulary are language-specific, characteristically Tzeltalan. In addition to vertical uses, landslope UP/DOWN is a feature of their early uses for $\mathrm{mo} / \mathrm{ko}$, this landslope UP/DOWN being a language-specific notion, and for them, even a household-specific notion at first. ${ }^{17}$ This is even more emphatically the case for the nouns: ajk'ollalan 'uphill/downhill' are used by these children only in their landslope senses, although the input includes some vertical uses. ${ }^{18}$ (See examples in table 17.5.) The core semantics for both nouns and verbs is built perhaps at first around concepts of place; for the nouns ajk'ollalan these can be quite far-away places (e.g. the hot country fields where the family grows corn), while for the verbs molko they are at first quite locally restricted places (particular houses in the local compound, for example, to 
Table 17.5. Examples of "uphill/downhilllacross" relational nouns in their landslope senses (pooled data from five children). Relational nouns are shown in italics

\begin{tabular}{ll}
$\begin{array}{l}\text { Name } \\
\& \text { age }\end{array}$ & Example \\
\hline Xan $2 ; 2$ & pet kajal. 'Downhill Xpet.'
\end{tabular}

Xan 2;2 kajal. '(To) downhill.'

Xan 2;3 baem na jtatik alan. 'Gone (to) house (of) downhill-sir' (i.e. her grandfather)

Xan 2;3 bajt alan. 'Gone downhill.'

Lus 2;6 xkatal jejch. 'Sideways Xkatal.'

Mik 2;6 bajt kajal.

'Gone (to) uphill'

Xaw 2;6 jnn, talon ek i jejch i. 'Hm, I come too (to) the side.'

Pet 2;9 ay ta alan . . ay ta jejch ... alan to xan. 'It's to downhill, . . . to the side. More downhillwards.'

Pet 2;11 sjojk'o kichan ta jejch. 'My cousin tothe-side asked.'

Xan 3;0 mach'a wixtikil, macha ay i li' ta ajk'ol i. 'Which sister, who is it here to uphill?'

Xaw 3;1 li' ta alan i. 'It's here to downhill.'

Lus 3;1 bajtix ta a'tel ek' i me'tik ta alan. 'Downhill Mrs. has gone to work.'

Lus 3;1 ja' i jNik li' ta kajal i. 'It's the Nik here uphill.'

Xaw 3;1 ja' i li' ta alan i ... a ta jejch. 'It's here to downhill, . . to the side.'

Lus 3;2 ja'i lum ta kajal lum ta snaik Nike, lum lum ta sna kajal Nike. 'It's there uphill, there at Nik's house, there at Nik's uphill house.'

Lus 3;2 ta yajk'ole li' talotik xan wojei. 'To its uphill [uphill = south side of house] here we came again yesterday.'

Lus 3;6 . . ya ka'y xan tza'nel jo'tik lum a ine ta yanil retrina. '. . we're going again for a shit there below [downhillwards of] the latrine.'
Context

identifying Xpet as the person asked about in previous utterance

reply to question about where she wants to go

reply to question about where her father has gone

reply to question: where's father?

reference to dog named Xkatal who lives across slope of land re house of his grandmother, uphill/South of his own house to kitchen house, across the slope from their two other houses

toy on patio

identifying person

querying identity of person

at the other house

identifying person as 'downhill Mrs., not where 'Mrs.' is working

identifying which Nik is referred to

where she's left something

identifying where $X$ happened

describing her and her playmate's movements circumnavigating the house

downhillwards of the latrine is on the same level as the latrine, but north of it. 
Table 17.5 (cont.)

Name

\& age Example

Context

Lus 3;6 . . la stamike i keremetik ta jejch.

'... the acrossways boys found it.'

identifying which boys - the ones who

live acrossways

Lus 3;6 te xa'wak' ta yanil a, yanil a'basoe. 'Put it there at its-underneath (of) your cup.'

telling sibling to put something

vertically underneath her cup

Lus $3 ; 8 \quad \ldots$ lum yajk'ol na lumine. ". . . over above the house over there.'

i.e. uphillwards (south) of the house over there

Lus 3;8 ju' baemon me ta julel ta yajk'ol na Albina jo'tik i. 'Hm, we went for shots (to the clinic) above Alvina's house.'

Lus 3;9 la nutz chitame i lum ta jejch. 'He chased a pig there at across.'

identifying where the pig was chased: at a place across the lay of the land

Lus 3;11 lum ay ta yanil mantarinae. 'There it is reference to lost ball below (downhillwards of) the mandarin tree.'

Lus 3;11 taojbe me ta yanil tuwa men me'. 'It's been found below the waterpipe.'

Lus 4;1 li' me ta yanil ini tajuntik li' ta ajk'ol a kili. 'Here below our uncle, here uphill I saw it.'

Lus 4;3 yu' ma jichuk a jelawon ta ajk'ol li' ta i.e. uphillwards (south) of it sna mejun a'wil ini xi. “ "... I crossed above Aunt's house here," she said.'

downhillwards of the waterpipe

reporting event she saw downhill from uncle's house and uphill from her own

i.e. south of Aunt's house

which one "ascends" or "descends" if they are arrayed along the South/North axis, or "goes across" if they are situated across the lay of the land from each other). Only gradually are the places associated with mo/ko and ajk'ol/alan combined with increasing geographical knowledge so that a general landslope direction abstracted from the idiosyncrasies of local spatial layouts enters the semantics of these words.

The place-linked specificity of the child's Absolute system lasts for a long time, although the number of places related in the system gradually increases. Children do generalize across contexts; molko usage is not restricted to exactly what is heard in the input, but extends to the motion of movable (and therefore sometimes novel) objects into trees, onto beds or other furniture, up onto the roof, to and from particular houses or other landmarks. By about the age of $3 ; 6$, children use molko productively for certain kinds of motions: talking about motion from house to house in the local arena, and about movement to and from certain named places. (See 
examples in table 17.2.) The molko verbs seem at first to be restricted to animates (including cars and toy cars), although this is not the case for adults. The use of these verbs by age 4 , in explicit contrast sets that include the "acrossways" terms (distinguishing "uphill/downhill/across"), confirms the language-specific nature of the terms as forming an Absolute system based on the lay of the land. ${ }^{19}$

\subsection{Data from interactional "space games"}

In children's natural production the use of the UP/DOwN vocabulary for small-scale spatial relations (saying, for example, $\mathbf{X}$ is 'uphill' or 'downhill' of $\mathrm{Y}$, of moveable objects on a tabletop) is rare, since it is rarely necessary to be so explicit. In an attempt to establish the degree of productivity of children's Absolute system, I therefore engaged a group of older children, aged 4 to 12 , in interactional tasks designed to prompt such usage. These "Farm Animal games" are played by two players visually screened from each other, one of whom (the Director) describes a spatial array of toy farm animals set out on a table in front of him; from his instructions the other player (the Matcher), has to reproduce the array with an identical set of farm animal toys on another table. ${ }^{20}$ In these games, adults routinely use the Absolute system to distinguish spatial relations, and some children of 4 are able to follow the instructions for placement in terms of Absolute (South/North) 'uphill/downhill,' albeit with some difficulty:

(1) (CL, a girl of 4;1, is the Matcher; the Director is $\mathrm{MN}$, her father):

MN: jo', ta yolil ta meru yolil. jitza to koel alan teb li' ta stojol yajk'ol te' $i$.

'Yeah, at the middle [between the two toy trees], at the real middle. Pull it [toy pig] downhillwards, downhillwards downhill a bit, here at the front of the uphill-side of the tree.'

CL: ajli'i.

'Oh here.'

MN: te' a mene eso.

'There. That's it.'

In production of the same novel tasks, when a child operates as the Director, we find adult-like usage (for example, 'Put the cow uphillwards of the horse, facing acrossways') in one child by $5 ; 8$, and in four others between the ages of 7 and $8 .{ }^{21}$ Some of the children in this production task are using the system indoors, without visual access to the lay of the land, and using the abstract South/North slope as the reference axis. The production of Absolute spatial relators is fluent, accurate, and productive in this task (although we still get some errors in interpretation due to the local slope/overall slope ambiguity). The existence of local slope misunderstandings in Farm Animal games even at age 7-8 suggests that for some 
children the meanings for the intransitive verbs molko stay for a long time too specific, not having yet been generalized to the overall South/North slope of land. Alternatively, the children may have all the correct meanings but misapply the pragmatic rules governing when the words should be understood as referring to overall slope instead of local slope.

There is thus good evidence for productivity of the Absolute system, even in novel tabletop tasks, by the age of 7-8. This is not to say that the children's mastery is equivalent to that of adults at this point. There are several thresholds for which we have not yet pinned down the point at which children attain adult competence. These are:

1. How "productive" is the uphill/downhill system in children of 2-3? For example, can they talk about 'granny-uphill' as 'granny-downhill' if they are currently located above her, on the local or Absolute slope? Can they choose between 'ascend' and 'descend' to refer to going to her house, depending on where they are? Or is there, instead, a rigid one-to-one correspondence between places or persons and their corresponding location-specifier, as if it were a name?

2. At what point can the children use or understand the words according to the Absolute system even when this is in conflict with the visual scene (for example, describing one object as higher than another, meaning to its South, even when it is actually lower in terms of local positioning)?

3. When can children use this system in all the situations in which adults do, keeping constant track ("dead-reckoning") of where uphill (South)/ downhill (North) are, even in unfamiliar places, at night, etc.?

These questions are currently under investigation. But what is clear at this point is that Tzeltal children do master this system, with at least a limited degree of productivity, at an early age, by at least $4 ; 0$. They are capable of using it projectively to describe small-scale spatial layouts in novel situations (i.e. not a context their normal life provides) by at least 7 or 8 , in some cases even younger.

\section{4}

\section{Discussion}

Children's mastery of the Tzeltal Absolute system (perhaps in a restricted way) by age 4 presents puzzles on two counts: the semantic complexity of the vocabulary, and the cognitive complexity of the frame of reference it involves. On the semantic side, we need to explain both the children's early willingness to entertain language-specific meanings for the path-incorporating motion verbs and the associated directionals and nominals, and the slowness with which they abstract from their initially place-linked meanings to a more general landslope meaning. On the cognitive side, children's early learning of the Tzeltal Absolute system in a language-specific manner 
raises the possibility that exposure to linguistic categories in appropriate nonlinguistic contexts may induce precociously early development of cognitive categories which, without exposure to such a language, would not be expected at that stage of development. This is because a proper mastery of this system (using fixed angles to calculate spatial relationships on the horizontal) presupposes Piaget's Euclidean stage of spatial cognition. On Piagetian grounds one would not expect children to have early use of an Absolute (Euclidean) system; the relevant Euclidean conceptual development occurs in the Western children tested by Piaget and his colleagues around the ages of 8 or 9 (see Piaget, Inhelder, \& Szeminska 1960; Brown \& Levinson in press). Thus even the limited productivity of children's UP/DOWN system by age 4, and certainly children's ability to use it for calculating spatial relations in a novel task prior to age 8 , are very suggestive for the possibility that language affects cognitive development. ${ }^{22}$

Turning to the semantic complexity issue, I will propose an explanation for the characteristics of Tzeltal children's early spatial verbs based on the verb semantics of the language itself.

\subsection{The verb specificity hypothesis}

An important typological property of Tzeltal is the highly specific semantics of verb roots; transitive and "positional" roots ${ }^{23}$ tend to be restricted to very limited sets of activities, and they distinguish events partly on the nature of the arguments they can take. There are, for example, many different verbs for eating depending on the characteristics of what you eat, and many different verbs for holding or carrying something depending on its shape and how you carry it (see figure 17.2). The same applies to verbs of position, cutting, breaking, insertion, extraction, and many others. These are basic-level verbs in Tzeltal, in the sense of Rosch (1978): that is, they are the unmarked way to label such events. We may contrast, for example, the basic-level English verb eat as opposed to its hyponym munch, with the

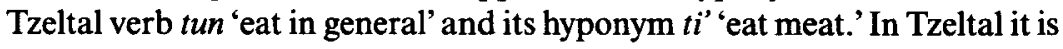
the 'eat meat' verb, and its cohorts 'eat crunchy things,' etc., which are basiclevel verbs in terms of frequency and unmarkedness. Unlike most basiclevel verbs in Indo-European languages, the Tzeltal verbs are like classifiers for kinds of activities, specific in terms of the nominal arguments they can take. $^{24}$

These kinds of verbs are prominent in children's vocabularies at the oneword stage (see examples in table 17.6). ${ }^{25}$ Perhaps the tendency to verb specificity in Tzeltal has an effect on the child's further hypotheses about verb meanings, and, in particular, about the meanings of motion verbs. Figure 17.3 illustrates the specific semantics of Tzeltal Path+Motion verbs; 


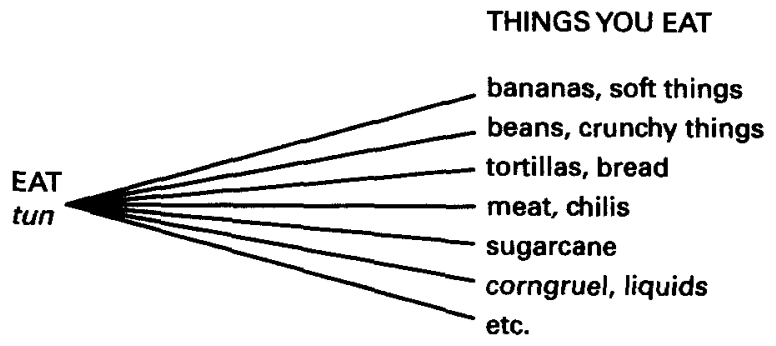

VERBS FOR EATING

$10^{\prime}$

$\boldsymbol{k}^{\prime} u x$

we'

$t i^{\prime}$

$t z^{\prime} u^{\prime}$

uch'

etc.

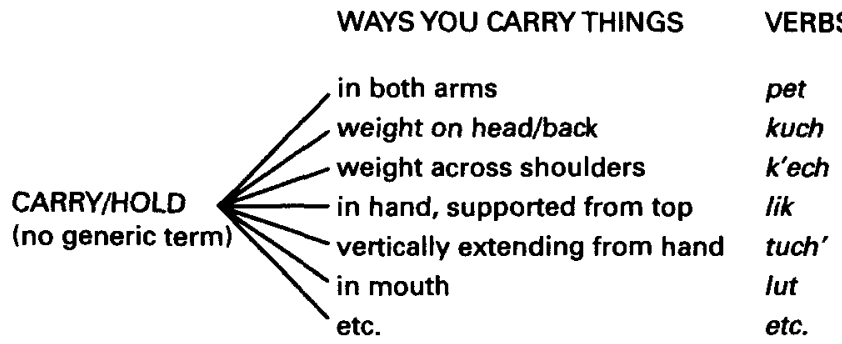

Fig. 17.2 Semantic specificity in Tzeltal verbs.

we can see how a Tzeltal child might extrapolate, from the specificity of verb meanings she has already learned, to an analogous specificity in the meanings of molkoljelaw 'ascend/descend/go across.' That is, on analogy with the semantic specificity of transitive and positional verbs, it is perhaps a reasonable hypothesis for Tzeltal children that motion too comes in different "kinds," depending on the characteristics of the path and goal. A presumption of specificity might lead children to choose very specific meanings for the verbs 'ascend' and 'descend,' such as 'go to particular places,' as illustrated in figure 17.4. Children might then resist generalization to different contexts unless they hear evidence in the input that such new contexts are places to which one "ascends" or "descends." Adhering to such a policy means that it can take a long time before what these contexts have in common - the fact that they are arrayed along an uphill/downhill axis, or vertically - forms the basis for abstracting a more general meaning not attached to particular places but to the relative location of places along such an axis. It takes an even longer time before cumulative geographical knowledge allows children to form an even more abstract concept of the overall slope of the land falling from South to North: this occurs sometime 
Table 17.6. First thirty-five verbs used in data samples from two Tzeltal children at the one- to two-word stage, listed in order of emergence. Boldface indicates "heavy" verbs restricted to specific arguments, nonboldface indicates "light" verbs. Criteria: used at least twice; not a repeat of prior utterance; not a frozen formula; meaning clear in context.

Mik $(1 ; 5-2 ; 0)$ MLU [mean length of utterance] about 1

Xan $(1 ; 3-2 ; 2)$ MLU 1 to 1.43

ba 'go, gone'

la' 'come!'

we' 'eat [tortillas, corn-based foods]'

ak' 'give'

tzak 'take, grasp [in hand]'

jach 'get/stand up'

chu' 'suckle [breast]'

tza' 'shit'

poj 'take away, steal'

ay 'exist, be located'

tek' 'step on something [2-footed]'

muk 'cover over [with cloth]'

tak' '(I) can('t)'

way 'sleep'

ajch' 'get wet'

pet 'carry [in arms]'

k'an 'want'

chux 'pee'

pix 'wrap [in cloth]'

mes 'sweep [with broom]'

$k$-il 'I see'

chuk 'tie [rope-like thing]'

lo' 'eat [fruit, soft things]'

pas 'do, make'

laj 'finish'

pach 'be positioned [bowl-shaped object, upright]'

tz'ap 'insert [stick-like thing tightly]'

och 'enter'

kay 'open [hinged thing, door]'

tal 'come'

kux 'hurt'

xi' '(I) fear (it)'

ch'ay 'fall'

pol' 'wash [outside surface, hands]'

lap 'put on [clothes on body]'

we' 'eat [tortillas, com-based foods]'

chu' 'suckle [breast]'

ay 'exist, be located'

boj 'cut [with knife/machete]'

k'ux 'eat [beans, crunchy things]'

(ma) na' 'don't know'

ba 'go, gone'

jun 'accompany'

pet 'carry [in arms]"

ch'ay koel 'fall down'

tam 'pick up, gather [thing dropped or fallen on ground]'

lo' 'eat [fruit, soft things]'

chik' 'insert [wood into fire]'

ta 'reach/find it'

xi' '(I) fear (it)'

way 'sleep'

tij 'play [radio, tape recorder]'

ak' 'give'

laj 'die, finish'

k'opoj 'speak'

tal 'come'

poch' 'peel [skin off fruit or animal]'

kux 'hurt'

och 'enter'

juch' 'grind [corn]'

tz'us 'close [door]'

k'ej 'put away'

lok' 'exit'

til 'burn [flame, flashlight]'

tek' 'stand [on two legs]'

k'an 'want'

il 'see'

puk' 'mix [corngruel with hand]'

xet' 'break [flexible flat thing]'

tuy 'cut [meat, acrossways]' 


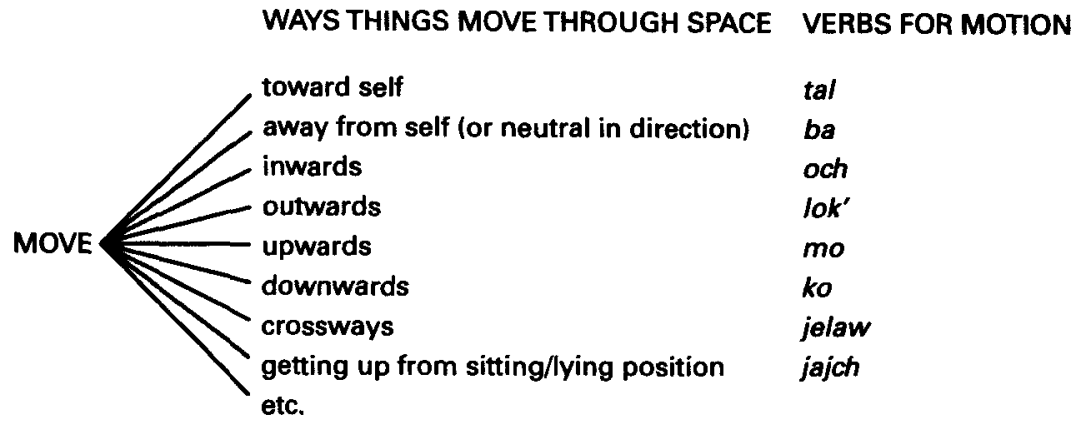

Fig. 17.3 Semantic specificity in Tzeltal motion verbs.

you mo ('ascend') to $\left\{\begin{array}{l}\text { house for sleeping } \\ \text { granny's house } \\ \text { San Cristobal } \\ \text { town } \\ \text { school } \\ \text { clinic } \\ \text { up in trees, up stumps, into bus/truck } \\ \text { etc. }\end{array}\right.$

you ko ('descend') to $\left\{\begin{array}{l}\text { house for cooking/eating } \\ \text { local fields } \\ \text { the ranch } \\ \text { alan (downhill fields) } \\ \text { down from trees, stumps, bus/truck, bed } \\ \text { etc. }\end{array}\right.$

you jelaw ('cross') to $\left\{\begin{array}{l}\text { side house } \\ \text { coffeeplots } \\ \text { neighbor's house } \\ \text { along path across slope of land above house } \\ \text { etc. }\end{array}\right.$

Fig. 17.4 Child's UP/Down verb meanings: motion via path comes in different "kinds." 
between the ages of 5 and 8, judging by the data from our Farm Animal games.

The argument here is similar to a proposal made by Carey (1978) for the semantics of the English word tall (see also Keil \& Carroll 1980.) Carey argued that children's immature meanings for relational words of this sort in English are probably best captured by a "missing features plus haphazard examples" theory, with tall at first closely linked to specific instances of use, its meaning not necessarily integrated in terms of features across different instances (e.g. tall for buildings being based on different criteria than tall for people). My proposal is that a propensity to construct word meanings in this fashion might be favored or disfavored by general properties of the language's semantic structure (see also Bowerman, de León \& Choi 1995; Choi \& Bowerman 1991).

Such a semantic specificity bias would make for conservative learners, thus helping Tzeltal children to get the language-specific meanings early by disinclining them to overgeneralize verb meanings. The mechanism by which such a bias comes to affect Tzeltal children's hypotheses about what verbs can mean could be a simple associative mechanism such as that proposed by Linda Smith, ch. 4 of this volume. At present this is just a hypothesis; further evidence - for example experiments with novel-verb learning would be required to confirm that Tzeltal children do indeed operate with such a verb-learning bias. Other evidence could come from children's early "errors" in assigning word meanings, e.g. associating words with meanings that are more restricted than is warranted by adult usage. ${ }^{26}$

Such a bias does not necessarily develop by the one-word stage, since it would require some exposure to and use of the language. It is thus distinct from the specificity of children's "holophrastic" early word meanings, where the word "means" or indexes the whole context of its use; such meanings are (for some children, and some words) a feature of the early oneword stage (Barrett 1982; Tomasello \& Brooks 1999). In Tzeltal children's acquisition of the Absolute system vocabulary, the shift from contextdependent meanings to an increasingly abstract symbolic meaning (beyond place-specificity to local slope, and beyond local slope to South/North land slope) is a more drawn-out process. The symbolic basis for South/North land slope UP/DOWN relies on children's geographical knowledge, which gradually increases in the preschool years. Nonetheless, there is evidence that the core uses of the terms are related for the child - that they are not simply attached to a list of arbitrary places. For example, children of 2-3 can point to places they describe in "uphill/downhill" terms, and a sense of their landslope spatial relations is visually apparent in the open valley of this community, as well as kinetically apparent in the effort required to go there (easy downhill, hard uphill; children are often required to walk down- 
hill, but are carried uphill). Certainly by age 4 , by the time children are using the system explicitly and productively in a relational way for small movable objects, even on flat terrain (e.g. 'the ball is downhillwards of the water tap'), it is clear that they have meanings for 'up/downhillwards' that are generalized at least to the local land slope. The verb specificity hypothesis would help them acquire such meanings, and predispose them to limit the meanings to the local land slope for an extended time.

Such a bias would of course be only part of the story of how Tzeltal children learn the meanings of molkoljelaw 'ascend/descend/go across.' They do, of course, have to attend to the contexts of use, infer the intentions of speakers when they use these verbs, and abstract what is common across different instances of $m o$, in contrast to $k o$, in contrast to jelaw. They could be helped by the consistent semantic relationship between these verbs and the corresponding nouns in the same frame: people regularly say things like $k$ o bel ta alan 'He descended away to downhill.' The fact that children at first use the "uphill/downhill" nouns like place names, and only gradually acquire their relational usages ("up/down in relation to X"), is likely to be closely tied to the place-linked specificity of path verbs. Children are perhaps helped in formulating an uphill/downhill axis and locating places along it by very consistent input (motion to certain places is routinely described with "ascend/descend" verbs, rather than the more general "go"), as well as by adults' accurate pointing in collocation with Absolute usage. The semantic structure of the language, and the hypothesized verbspecificity bias it engenders in Tzeltal children, would thus work in conjunction with many context-dependent cues to the system.

\subsection{Semantic specificity in typological perspective}

The hypothesis I have proposed concerns semantic specificity within the Tzeltal class of verbs. Such specificity is a typological feature of Mayan (and, indeed, of many other Mesoamerican) languages. There are two additional typological features of Tzeltal - and of Mayan languages in general that are relevant to this hypothesis. The first is that spatial relations are encoded in nouns and verbs in Tzeltal, rather than in the prepositions, postpositions, or case markers of more familiar languages. There is only one allpurpose preposition in Tzeltal. Spatial relations involving an UP/DOWN contrast are, as we have seen, conveyed by verbs meaning things like 'to be high up, 'to be low down,' 'to ascend' or 'to descend,' by adverbials that are transparently derived from verb roots and mean 'upwards' or 'downwards,' and by possessed nouns meaning things like 'its-top/uphillward-side' and 'its-underneath/downhillward-side.' Spatial meanings encoded in verbs and nouns ("content words") present a very different problem to a child than 
spatial meanings encoded in grammatical morphemes ("functors") like prepositions or case markers. Spatial relations encoded in nouns and verbs (in "open classes," or - more accurately for Tzeltal - in closed subsets of open classes) are more context-specific, tied more closely to content, to particular activities and things, while functors, to the extent to which they are grammaticalized, have abstracted from the contextual specificity a spatial core which then applies across many different kinds of contexts. ${ }^{27}$ Having the functional load of spatial reference carried by nouns and verbs is one source, then, of specificity in Tzeltal spatial language.

The second relevant typological characteristic of the language concerns the distribution of information in an utterance. In Tzeltal, the semantic division of labor between verbs and nouns is rather different from that in IndoEuropean languages. In the latter, nouns tend to encode specific properties of objects, and verbs to denote relations between objects while remaining agnostic as to the properties of objects whose relations they denote (Gentner 1978, 1982, ch. 8 of this volume). In the Mayan languages, many basic-level verb roots ${ }^{28}$ encode properties of the objects to which they can apply (e.g. pach 'be positioned [bowl-shaped object canonically upright]'; see de León, ch. 18 of this volume, for examples). Inanimate noun roots, by contrast, are often unspecified as to the form of their referents, denoting only the material they are composed of (e.g. "wood-stuff," "banana-stuff," "coffee-stuff;" see Lucy 1992; Gaskins \& Lucy, ch. 9 of this volume).

These differences between Mayan and Indo-European languages suggest that languages may actually differ broadly in terms of which word classes are characterized by specific and which by more general kinds of meanings. Suppose we could operationalize a measure of specificity across word classes - simplistically, this might be thought of in terms of number of features, or in terms of meaning inclusion (the meanings of general words being included in those of their more specific hyponyms). We could then compare word classes with a tendency to highly differentiated meanings to those with a tendency to general meanings by calculating the average number of features involved in their meanings. A notional cline of specificity in word classes is illustrated in figure 17.5: for a language like English such a cline might have common nouns at the most specific end, followed by verbs and adjectives, and with prepositions and other grammatical morphemes at the most general end. But a cline for Tzeltal would have transitive and positional verb roots towards the specific end, followed by intransitive verbs, then common nouns, and with the one all-purpose preposition at the most general end. ${ }^{29}$ This sort of broad typological difference in the semantic organization of languages has implications for theories of spatial language; for example, it undermines proposed cognitive explanations (e.g. Talmy 1985; Landau \& Jackendoff 1993) for the supposedly 
Specific General

For English:

$\underset{\text { nouns }}{\text { common }}$ verbs $\longrightarrow$ adjectives —prepositions $\underset{\text { items }}{\text { grammatical }} \longrightarrow$

ForTzeltal:

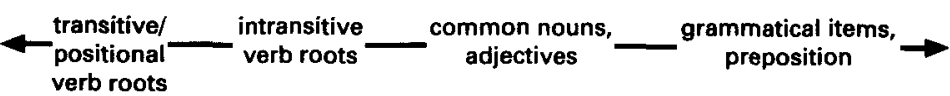

Fig. 17.5 Comparing specificity of meaning across word classes, across languages.

semantically bleached character of spatial morphemes. (See Slobin, ch. 14 of this volume, for additional arguments against such cognitive explanations.)

My proposal for a verb specificity bias in Tzeltal appears to run in the opposite direction to E. V. Clark's 1973 hypothesis based on IndoEuropean language data: that children begin with a preference for general word meanings, which they later modify by adding in more specific features. Although Clark (1993) no longer holds to her 1973 hypothesis, there are still current proposals, based on the high frequency of light verbs in children's early speech, that children tend to start with "light" semantically bleached verbs and that these play an important role in the acquisition of syntax (e.g. Hollebrandse \& van Hout 1994 for Dutch; Ninio 1999 for English and Hebrew). There is no evidence in Tzeltal children's speech of a tendency for early verbs to be "light": while a handful of light verbs do exist and are frequent in Tzeltal (e.g. ak' 'give,' pas 'do/make,' ay 'exist,' ich' 'get'), in children's early vocabularies these are vastly outnumbered by specific verbs (see table 17.6). More importantly, there is no evidence that Tzeltal children use light verbs as general-purpose verbs in lieu of more specific ones: from the start, a child wanting her belt retied will say things like "Tie it for me," using a specific verb, rather than expressing such a request with a general verb as in: "Do my belt up for me" (Brown 1998b).

\section{Conclusion}

The Tzeltal data on "uphill/downhill" acquisition reviewed here have a number of implications for theories of language acquisition and cognitive development.

First, proposed universal prelinguistic concepts like "vertical" do not seem to be providing ready-made semantic units which children start with 
in learning the Tzeltal Absolute vocabulary. Rather, learning the words in context provides the concepts, by a process of induction across instances of use, instances which include both vertical contexts and landslope contexts for the same words. Both the concepts and the predispositions for verb learning that $I$ have proposed are induced from the language itself, and are language-specific. Whatever the role of putative universal semantic primes may be in providing children with a starting point for learning word meanings in general (and that role is a hotly debated issue), they are not providing in any direct way a repertoire of privileged meanings onto which Tzeltal children map the spatial words of their language. The Tzeltal findings support the views of Tomasello and others on the importance of context in children's developing word meanings.

A second point arising from the Tzeltal data is that languages can vary in which word class generally carries the referential load, and that this has important implications for children's learning of their first language. In English, nominal arguments pick out their referents directly; in Tzeltal, the information necessary to pick out the referent is very largely encoded in the verb, at least for the transitive verbs like $t i$ ' 'eat meat' and the positional verbs like pach 'be positioned [bowl-shaped object canonically upright]' discussed above. On the assumption that at least part of what children are doing when they begin to use language is learning how to refer, if the referential load of the language they are exposed to is mainly carried in verbs, then, pace Gentner \& Boroditsky (ch. 8 of this volume), it doesn't seem surprising that verbs are what children tend to learn first. This may explain the early prominence of verbs in children's corpora in languages like Tzeltal, Tzotzil, and perhaps also Korean (see Choi 1997; Brown 1998b; de León 1999a, b, ch. 18 of this volume; contrast Gentner \& Boroditsky, ch. 8 of this volume).

The proposal that the semantic structure of previously learned words might influence children's hypotheses about what words can mean is not new. It is articulated in the work of Bowerman and her colleagues, ${ }^{30}$ who document children's early sensitivity to the semantic structure of their language, finding that the very earliest uses of words reflect their language-specific meanings. My proposal adds the claim that very general lexicalization properties of the language (e.g. what semantic features are likely to be lexicalized in verbs as opposed to nouns) may sensitize children to what the semantic weight of different word classes is likely to be, providing a basis for languagespecific hypotheses about possible word meanings which may extend throughout the preschool years. The proposal developed here is that the language Tzeltal children hear provides many different verb labels for a given domain of activity, and thereby affects the hypotheses they bring to bear on what new verbs can mean. This argument is also in harmony with Slobin's proposal (ch. 14 of this volume) of "typological bootstrapping." We are now 
beginning to have detailed longitudinal data from children learning languages with a semantic structure radically different from those predominantly studied by students of child language development. ${ }^{31}$ We will thus soon be in a position to test such hypotheses more directly.

\section{NOTES}

I am grateful to Melissa Bowerman, Wolfgang Klein, Lourdes de León, Stephen Levinson, and David Wilkins, for critical comments on earlier versions of this chapter.

1 The community of this study is the remote rural hamlet of Majosik', in the Tzeltal-speaking municipio of Tenejapa, Chiapas, Mexico. There are some 150,000 speakers of Tzeltal in Chiapas, and perhaps an equivalent number of speakers of Tzotzil in the closely related Tzotzil communities (see de León, ch. 18 of this volume). An "uphill/downhill" system of spatial description is found in many Mayan communities throughout this mountainous region.

2 For example, Bowerman (1989, 1996a, b), Choi \& Bowerman (1991), Bowerman, de León, \& Choi (1995), Bowerman \& Choi (ch. 16 of this volume), de León (ch. 18 of this volume).

3 For example, the early acquisition of the prepositions corresponding to $\mathrm{NN}$ and ON in English and related languages has been attributed to the universal early availability of the topological concepts of containment and support; similarly, the early acquisition of UP and DOWN was attributed to the perceptually given salience of the vertical dimension (Bloom 1973; Nelson 1974; Miller \& Johnson-Laird 1976; Johnston \& Slobin 1979; E. V. Clark 1980).

4 See Carey, ch. 7 of this volume.

5 For example the Mutual Exclusivity Principle, the Whole Object Constraint, the Shape Bias. For a recent summary of these "developmental lexical principles" see Golinkoff, Mervis, \& Hirsh-Pasek 1994.

6 We can compare "general" and "specific" verbs in a given semantic domain (e.g. "eating verbs") in terms of meaning inclusion, with the former (e.g. "eat, in general") being a proper subset of the latter ("eat meat," "eat tortillas," etc.) in terms of componential features (E. V. Clark 1973, Gentner 1978).

7 Although I use the South/North contrast to clarify one sense of the "uphill/downhill" terms, Tenejapans themselves do not think in terms of North/South/East/West and most of them do not know the Spanish cardinal terms.

8 It does not exist for the monolingual speakers of the present study. Speakers who are bilingual in Tzeltal and Spanish may adopt (part of) a Front/Back/Left/ Right system from Spanish.

9 These verbs are used only for change of location, not for posture changes, and only for spontaneous motion (a causative suffix is required to indicate caused motion), just as in Tzotzil. See Talmy (1985) for lexicalization patterns of motion verbs; see also de León (1994 and ch. 18 of this volume) for Tzotzil.

10 As this chapter concentrates on the acquisition of UP/DOWN spatial relations, vocabulary acquisition for this transverse axis will not be considered here. See, however, Brown \& Levinson (in press). 
11 The overall slope is South/North in Tenejapa, but it varies in different communities; the neighboring Tzotzil community of Zinacantan, for example, slopes down to the West and their system is correspondingly shifted $90^{\circ}$.

$12 \mathrm{I}$ am at present not taking a stand as to whether the multiple meanings discussed here are at the lexical level (the terms being polysemous) or at the utterance level (the terms being semantically general across the three different bases for establishing an UP/DOWN distinction, with pragmatic rules providing an interpretation in context). The clear semantic relationship among the three uses of these terms (vertical, local land slope, South/North land slope) argues for monosemous meanings for the UP/DOWN terms, with "higher/lower" as the core semantic feature; things may be higher/lower at any angle from the horizontal. The fact that there are other Mayan communities with analogous systems based on different geographical features (the direction of sunrise/sunset, or the flow of a river, for example) suggests a metaphorical process common to them all.

13 The data were collected over the course of three years of regular six-weekly visits to children in the five extended households. It comprises more than 600 hours of videotaped and/or audiotaped natural interaction, supplemented by more structured sessions with children up to age 12. This is work in progress: data are still being collected and analyzed.

14 Children in this society seem to be somewhat late talkers; of the five focal children in my study, all were still in the one- to two-word stage at age two. This is likely to be related to childrearing practices: in this community babies and small children are talked to very little, and are not treated as interlocutors until they are walking (Brown 1998c).

15 For example, a sample of two hours' input to an 18-month-old girl yielded only three instances of the "ascend/descend" verbs. This low frequency is partly due to the fact that, in Tzeltal, spatial language is encoded in nouns and verbs, rather than in semantically bleached (and hence appropriate for many different kinds of contexts) grammatical particles. It is also doubtless due to the "here and now" character of talk with small children, where deictics, pointing, and other nonexplicit forms are normally contextually appropriate. This may account for the relative absence of this vocabulary at the one-word stage, as was also found by de León (ch. 18 of this volume) for Tzotzil children. The more frequent motion verb 'go' is, in fact, present in Tzeltal children's productions at the oneword stage, and the 'come/go' verbs precede 'ascend/descend' in acquisition, but they do not seem to be overgeneralized to situations where motion is appropriately described with 'ascend/descend.'

16 For example balch'oj 'tip over sideways [of a cylinder-shaped object]' being used for a toy of any shape tipping over in any direction, including end-overend.

17 It is household-specific in the sense that it depends on the orientation of their household compound and the local slope of the land where it is set: some households are oriented South/North, others on a local slope at some other angle. In both cases, children of this age use the local slope and arrangement of houses to establish their Absolute axis.

18 For example, one child's mother says: ixtal kalantik i a'wala tzek $i$ (lit: 'Come let's "down[hill]" your little skirt,' meaning 'Let's pull your skirt down [to its proper level].' (This is actually a verbal use of the noun alan 'downhill.') 
19 This point was first demonstrated for the Tzotzil Absolute system by de León (1994).

20 The task was designed by members of the Cognitive Anthropology Research Group at the Max Planck Institute for Psycholinguistics, Nijmegen; see their Space Stimuli Kit 1.2, June 1993.

21 This task has been carried out to date with a total of twenty children (ranging from age 4;1 to 10) acting as Matcher, and ten children (from age 5;7 to 12) acting as Director. Here I am reporting only on the six games for which the data are fully processed.

22 Further work needs to be done to establish whether language really is affecting cognitive development in this case. First one must ascertain what exactly in the Tzeltal Absolute system is the analogue of Piaget's Euclidean thinking. Secondly, one must rule out the possibility that children are getting the right answer for the wrong reasons - for example, using the local slope of land as a reference line, as in Piaget's table edge task, against which to line up a spatial array visually. In addition, both cognitive testing and more controlled linguistic testing of a larger group of Tzeltal children would be necessary. These are tasks for future research.

23 Positionals are a large class of roots in Mayan languages with distinct derivational morphology, often combining semantic features of shape, position, configuration; they are important in predicating location (Brown 1994; Haviland 1994a, b; see also de León, ch. 18 of this volume). These comprise perhaps a third of the verbal lexicon, on analogy with Tzotzil (Haviland 1994a).

24 See Brown (1994), Brown \& Levinson (1993a), for analyses of the semantics of these verbs in Tzeltal; see Haviland 1994a for Tzotzil. See also Choi \& Bowerman 1991 for similar semantics of early verbs in Korean.

25 For further details about Tzeital children's first verbs see Brown (1997, 1998a, b, c. See also de León (ch. 18 of this volume), for Tzotzil.

26 For example, Suzanne Gaskins (p.c.) reports an American child's misunderstanding of upstairs to mean 'place where we sleep' (an error only discovered when the family moved to a house where they slept downstairs). Similarly, Choi \& Bowerman (1991:107) report a Korean child's initial misunderstanding of a verb meaning 'cause to go up' to mean 'put away where object belongs,' an error which they attribute to the child's recently having learned many verbs that do incorporate features of the Ground.

27 See Slobin, ch. 14 of this volume, for a related argument. See also Landau \& Jackendoff (1993).

28 Roots are the semantic packages in Mayan languages relevant for this comparison; not the syntactic categories $\mathrm{N}$ and $\mathrm{V}$. Roots may freely combine with derivational morphology to change syntactic category (e.g. from $\mathrm{N}$ to $\mathrm{V}$ and vice versa), but the semantic specificity of the root is retained.

29 I owe the current formulation of this argument to discussion with Wolfgang Klein (p.c.). Gentner (1988) has also argued that English verbs are intermediate between nouns and prepositions, on a scale ranging from prepositions and other "closed-class" items at the most linguistically determined end to concrete (basic-level) nouns and names for individuals at the most cognitively/perceptually determined end.

30 For example: "Korean children ... are not prompted to analyze out Path as an 
abstract component of motion events as strongly as are learners of English, and this may account for their delay in acquiring those Path verbs that do express Path in relatively pure form. Instead, they are encouraged to classify motion events on the basis of Path meanings admixed with causativity and properties of the Figure and Ground" (Choi \& Bowerman 1991: 114).

31 Longitudinal work on Korean has perhaps been the first to prompt language acquisition researchers to reappraise theories based primarily on IndoEuropean semantic structures (see Choi 1997). Among longitudinal studies on the "exotic" languages of largely illiterate, unindustrialized societies, the Mayan languages are especially well represented (K'iche' [Pye 1992], Yucatec [Pfeiler \& Martín Briceño 1997], Tzotzil [de León 1994, 1997, 1999a, b, ch. 18 of this volume], and Tzeltal (Stross 1969; Brown 1993; 1997, 1998a, b, c; Brown \& Levinson, in press), making a potential for detailed crosslinguistic analysis within this language family.

\section{REFERENCES}

Barrett, M. 1982. The holophrastic hypothesis: conceptual and empirical issues. Cognition 11: 47-76.

Bloom, L. 1973. One word at a time: the use of single word utterances before syntax. The Hague: Mouton.

Bowerman, M. 1989. Learning a semantic system: what role do cognitive predispositions play? In M. L. Rice \& R. L. Schiefelbusch (eds.), The teachability of language. Baltimore, MD: Paul H. Brookes, 133-169.

1996a. The origins of children's spatial semantic categories: cognitive vs. linguistic determinants. In J. J. Gumperz \& S. C. Levinson (eds.), Rethinking linguistic relativity. Cambridge: Cambridge University Press, 145-176.

1996b. Learning how to structure space for language: a crosslinguistic perspective. In P. Bloom, M. A. Peterson, L. Nadel, \& M. F. Garrett (eds.), Language and space. Cambridge, MA: MIT Press, 385-436.

Bowerman, M., L. de León, \& S. Choi. 1995. Verbs, particles, and spatial semantics: learning to talk about spatial actions in typologically different languages. In E. V. Clark (ed.), The proceedings of the 27th Annual Child Language Research Forum. Stanford, CA: Center for the Study of Language and Information, 101-110.

Brown, P. 1993. The role of shape in the acquisition of Tzeltal (Mayan) locatives. In

E. V. Clark (ed.), The proceedings of the 25th Annual Child Language Research Forum. Stanford, CA: Center for the Study of Language and Information, 211-220.

1994. The INs and oNs of Tzeltal locative expressions: the semantics of static descriptions of location. Linguistics 32:743-790.

1997. Isolating the CVC root in Tzeltal Mayan: a study of children's first verbs. In E.

V. Clark (ed.), The proceedings of the 28th Annual Child Language Research Forum. Stanford, CA: Center for the Study of Language and Information, 41-52. 1998a. Early Tzeltal verbs: argument structure and argument representation. In E. V. Clark (ed.), The proceedings of the 29th Annual Child Language Research Forum. Stanford, CA: Center for the Study of Language and Information, 129-140. 
1998b. Children's first verbs in Tzeltal: evidence for an early verb category. Linguistics 36: 715-753.

1998c. Conversational structure and language acquisition: the role of repetition in Tzeltal adult and child speech. Journal of Linguistic Anthropology 8: 1-25.

Brown, P., \& S. C. Levinson. 1993a. "Uphill" and "downhill" in Tzeltal. Journal of Linguistic Anthropology 3: 46-74.

1993b. Shaping the world: semantic distinctions of shape and orientation in Tzeltal roots. Paper presented at the annual meeting of the American Anthropological Association, Washington, DC.

In press. Frames of spatial reference and their acquisition in Tenejapan Tzeltal. In L. Nucci, G. Saxe, \& E. Turiel (eds.), Culture, thought, and development. Mahwah, NJ: Lawrence Erlbaum.

Carey, S. 1978. The child as word learner. In M. Halle, J. Bresnan, \& G. A. Miller (eds), Linguistic theory and psychological reality. Cambridge, MA: MIT Press, $264-293$.

Choi, S. 1997. Language-specific input and early semantic development: evidence from children learning Korean. In D. I. Slobin (ed.), The crosslinguistic study of language acquisition, vol. 5: Expanding the contexts. Mahwah, NJ: Lawrence Erlbaum, 41-133.

Choi, S., \& M. Bowerman. 1991. Learning to express motion events in English and Korean: the influence of language-specific lexicalization patterns. Cognition 41: 83-121.

Clark, E. V. 1973. What's in a word? On the child's acquisition of semantics in his first language. In T. E. Moore (ed.), Cognitive development and the acquisition of language. New York: Academic Press, 65-110.

1980. Here's the top: nonlinguistic strategies in the acquisition of orientational terms. Child Development 51: 329-338.

1993. The lexicon in acquisition. Cambridge: Cambridge University Press.

Clark, H. H. 1973. Space, time, semantics, and the child. In T. E. Moore (ed.), Cognitive development and the acquisition of language. New York: Academic Press, 27-63.

de León, L. 1994. Exploration in the acquisition of geocentric location by Tzotzil children. Linguistics 32: 857-884.

1997. Vertical path in Tzotzil (Mayan) early acquisition: linguistic vs. cognitive determinants. In E. V. Clark (ed.), The proceedings of the 28th Annual Child Language Research Forum. Stanford, CA: Center for the Study of Language and Information, 183-197.

1999a. Verb roots and caregiver speech in early Tzotzil acquisition. In B. A. Fox, D. Jurafsky, \& L. A. Michaelis (eds.), Cognition and function in language. Stanford, CA: Center for the Study of Language and Information, 99-119.

$1999 \mathrm{~b}$. Verbs in Tzotzil early syntactic development. International Journal of Bilingualism 3: 219-240.

Gentner, D. 1978. On relational meaning: the acquisition of verb meaning. Child Development 49: 988-998.

1982. Why nouns are learned before verbs: linguistic relativity versus natural partitioning. In S. A. Kuczaj II (ed.), Language development, vol. 2: Language, thought, and culture. Hillsdale, NJ: Lawrence Erlbaum, 301-334. 
1988. Cognitive and linguistic determinism: object reference and relational reference. Paper presented at the Boston Child Language Conference, Boston, MA, November.

Golinkoff, R. M., K. Hirsh-Pasek, C. B. Mervis, W. B. Frawley, \& M.Parillo. 1995. Lexical principles can be extended to the acquisition of verbs. In M. Tomasello \& W. E. Merriman 1995, 185-222.

Golinkoff, R. M., C. B. Mervis, \& K. Hirsh-Pasek. 1994. Early object labels: the case for lexical principles. Journal of Child Language 21: 185-215.

Haviland, J. B. 1994a. "Te xa setel xulem"(The buzzards were circling): categories of verbal roots in (Zinacantec) Tzotzil. Linguistics 32: 691-742.

1994b. Verbs and shapes in (Zinacantec) Tzotzil: the case of "insert." Función (University of Guadalajara) 15-16: 83-117.

Hollebrandse, B., \& A. van Hout. 1994. Light verb learning in Dutch. In Papers from the Dutch-German Colloquium on Language Acquisition. Amsterdam Series in Child Language Development, 3. Groningen: University of Groningen.

Johnston, J. R., \& D. I. Slobin. 1979. The development of locative expressions in English, Italian, Serbo-Croatian and Turkish. Journal of Child Language 6: 529-545.

Keil, F., \& J. J. Carroll. 1980. The child's acquisition of "tall": implications for an alternative view of semantic development. Papers and Reports on Child Language Development 19: 21-28.

Landau, B., \& R. Jackendoff. 1993. "What" and "where" in spatial language and spatial cognition. Behavioral and Brain Sciences 16: 217-238.

Levinson, S. C. 1996. Frames of reference and Molyneux's question: crosslinguistic evidence. In P. Bloom, M. A. Peterson, L. Nadel, \& M. F. Garrett (eds.), Language and space. Cambridge, MA: MIT Press, 109-169.

Lucy, J. 1992. Grammatical categories and cognition: a case study of the linguistic relativity hypothesis. Cambridge: Cambridge University Press.

Miller, G. A., \& P. N. Johnson-Laird. 1976. Language and perception. Cambridge, MA: Harvard University Press.

Nelson, K. 1974. Concept, word, and sentence: interrelations in acquisition and development. Psychological Review 81:267-285.

1996. Language in cognitive development: the emergence of the mediated mind. Cambridge: Cambridge University Press.

Ninio, A. 1999. Pathbreaking verbs in syntactic development and the question of prototypical transitivity. Journal of Child Language 26: 619-653.

Pfeiler, B., \& E. Martín Briceño. 1997. Early verb inflection in Yucatec Maya. Papers and Studies in Contrastive Linguistics 33: 117-125.

Piaget, J., \& B. Inhelder. 1967 [1948]. The child's conception of space. New York: Norton.

Piaget, J., B. Inhelder, \& A. Szeminska. 1960. The child's conception of geometry. London: Routledge \& Kegan Paul.

Pye, C. 1992. The acquisition of K'iche' Maya. In D. I. Slobin (ed.), The crosslinguistic study of language acquisition, vol. 3. Hillsdale, NJ: Lawrence Erlbaum, 221-308.

Rosch, E. 1978. Principles of categorization. In E. Rosch \& B. B. Lloyd (eds.), Cognition and categorization. Hillsdale, NJ: Lawrence Erlbaum, 28-46.

Slobin, D. I. 1985. Crosslinguistic evidence for the Language-Making Capacity. In 
D. I. Slobin (ed.), The crosslinguistic study of language acquisition, vol. 2: Theoretical issues. Hillsdale, NJ: Lawrence Erlbaum, 1157-1249.

Stross, B. 1969. Language acquisition by Tenejapa Tzeltal children. Unpublished doctoral dissertation, University of California at Berkeley.

Talmy, L. 1985. Lexicalization patterns: semantic structure in lexical form. In T. Shopen (ed.), Language typology and syntactic description, vol. 3: Grammatical categories and the lexicon. Cambridge: Cambridge University Press, 36-149.

Tomasello, M. 1992. First verbs: a case study of early grammatical development. Cambridge: Cambridge University Press.

Tomasello, M., \& P. J. Brooks. 1999. Early syntactic development: a construction grammar approach. In M. Barrett (ed.), The development of language. Hove: Psychology Press, 161-190.

Tomasello, M., \& W. E. Merriman (eds.). 1995. Beyond names for things: young children's acquisition of verbs. Hillsdale, NJ/Hove: Lawrence Erlbaum. 